УДК 37.033

\title{
АКТУАЛЬНОСТЬ ВОСПИТАНИЯ ЭКОЛОГИЧЕСКОЙ КУЛЬТУРЫ В НАЧАЛЕ ХХІ ВЕКА
}

Троян Ирина Сергеевна

преподаватель высшей квалификационной категории МБОУ Дубковская СОШ «Дружба»

Аннотация: Воспитание экологической культуры - актуальнейшая задача сложившейся социально-культурной ситуации начала XXI века. В условиях разностороннего глубочайшего экологического кризиса усиливается значение экологического образования в начальной школе как ответственного этапа в становлении и развитии личности ребенка. Закон «Об экологическом образовании», принятый во многих регионах России, ставит своей задачей создание системы непрерывного всеобъемлющего экологического образования и является основанием для поиска и разработки эффективных средств экологического образования населения. Анализ теоретической и методической экологической литературы, а также состояния практики экологического образования в начальных школах свидетельствует о необходимости совершенствования всей системы воспитательной работы с младшими школьниками, одной из приоритетной целей которой должно стать становление экологически грамотной личности, способной гармонично взаимодействовать с окружающим миром и осознающей свое место в Природе.

Ключевые слова: Экологическое воспитание, гуманное отношение, экологическая грамотность, социальная активность, окружающая среда.

\section{THE RELEVANCE OF ENVIRONMENTAL CULTURE EDUCATION AT THE BEGINNING OF THE XXI CENTURY}

\section{Troyan Irina Sergeevna}

\begin{abstract}
The education of ecological culture is the most urgent task of the current socio-cultural situation of the beginning of the XXI century. In the
\end{abstract}


conditions of the most diverse and profound ecological crisis, the importance of environmental education in primary school as a responsible stage in the formation and development of a child's personality is increasing. The law "On Environmental Education", adopted in many regions of Russia, aims to create a system of continuous comprehensive environmental education and is the basis for the search and development of effective means of environmental education of the population.

The analysis of theoretical and methodological environmental literature, as well as the state of the practice of environmental education in primary schools indicates the need to improve the entire system of educational work with younger schoolchildren, one of the priority goals of which should be the formation of an environmentally literate person who is able to interact harmoniously with the outside world and is aware of his place in Nature.

Key words: Environmental education, humane attitude, environmental literacy, social activity, environment.

«Если мы любим наших детей, мы обязаны нежно и бережно любить

Землю и передавать её грядущим поколениям во всём её многообразии и красоте, чтобы тёплым весенним днём десять тысяч лет спустя они смогли ощутить покой в море трав, полюбоваться пчелой, кружащейся вокруг цветка, прислушаться к пению жаворонка в небе и почувствовать радость жизни как таковой» Хью Х Илтис

Сложная экологическая обстановка в мире, её тяжёлые последствия, экология родного края, засорённость среды обитания - всё это вызывает необходимость способствовать экологическому образованию детей начиная с малых лет. Экологическое воспитание детей имеет важное социальное значение для всего общества: своевременно закладываются основы экологической культуры в человеческой личности.

Для детей характерно неустойчивое отношение к окружающей среде. Поэтому педагогам в своей работе важно способствовать накоплению детьми эмоционально позитивного опыта общения с природой, воспитывать у детей гуманное отношение к окружающему миру, формирование экологической грамотности учеников, осуществляя комплексный подход через различные виды деятельности. 
Ещё 20-30 лет назад проблемы экологии обсуждали в основном специалисты - биологи, а сейчас этот термин прочно вошёл в нашу жизнь и даже дети знают, что не надо портить «окружающую экологию». Экологическое образование в условиях современного экологического кризиса, для того чтобы быть эффективным, должно решать главную задачу: формировать экологически ориентированное сознание, по существу - новое видение мира. Экологически ориентированное сознание акцентирует единство, неотчуждённость человека и природы.

Целью экологического образования и воспитания является ответственность за все живое на планете Земля, углубление экологических знаний у детей, гуманного отношение к природе, формирование чувства сопричастности ко всему живому на Земле.

\section{Задачи:}

Образовательная:

- изучение условий жизни на Земле;

- изучение экологической проблемы Земли;

Воспитательная:

- воспитание чувства любви к природе и к окружающей среде,

- воспитание, добросовестного отношения к труду; положительного отношения к знаниям;

- воспитание дисциплинированности;

- воспитание умений работать в группе, в коллективе;

- воспитание эстетических взглядов

- воспитание гуманности, по отношению к животным, бережное отношение к природе, любви к природе, Родине.

С экологией как наукой дети знакомятся в школе. Поэтому именно в этом возрасте важно создать условия для развития у детей понимания того, что всё в природе взаимосвязано. Земля - наш общий дом, а человек - часть живого мира природы. Сегодняшние школьники будут жить в третьем тысячелетии, в быстро меняющемся мире с ухудшающейся экологией. Уже от них, их экологической грамотности, социальной активности, ответственности будет зависеть преодоление экологического кризиса, сохранение жизни на планете. Как раз в школьном возрасте, когда ребёнок впервые приобщается к миру природы, богатству и разнообразию её красок и форм, необходимо формировать первые представления об экологии, воспитывать бережное 
отношение и любовь к живому миру вокруг нас, частицей которого мы являемся.

Возникает вопрос, как воспитать у ребёнка чувство причастности к природе, отношение к планете как дому, ко всему живому как самоценности. Здесь необходимо найти баланс между некоторыми знаниями о природе и формированием эмоционального отношения к ней. В младшем школьном возрасте у ребёнка резко расширяется сфера познавательных интересов. Он смотрит в большой мир широко открытыми глазами, всё вызывает его интерес. Кроме того, формируется его отношение к окружающему. При систематической ориентировке на существенные признаки живых организмов и их жизненных проявлений в процессе игровой и практической деятельности ребенка в форме наглядных образов для него открываются не только внешняя видимость явлений природы, но и простейшие причинные и функциональные связи между ними. Таким образом, у ребёнка начинают складываться такие формы чувственного познания природы, которые важны не только для настоящего периода его развития, но и для будущей его взрослой жизни.

Ребёнок учится следовать определённым общественным нормам и правилам поведения, и, если в этот процесс будет включено не только формирование эмоционально - положительного отношения к солнцу, чистой воде, свежему воздуху, растениям и животным, но и норм поведения, не наносящего вреда всему живому, сберегающего и восстанавливающего природу, - это принесёт положительный результат не только в детстве, но и во взрослой жизни человека.

Мы привыкли к тому, что планета Земля дает нам все и в большом количестве, что никогда не задумывались над тем, а как она себя чувствует. Уничтожаются леса, загрязняются вода, воздух, земля. Нещадно истребляются животные, рыбы, птицы. В новое тысячелетие люди шагнули с очень серьезной проблемой экологии. Наша планета в опасности. Земля - это жемчужина космоса, и она ждет помощи от нас. Дети, как и взрослые должны оберегать, любить свою планету. Ведь именно детям придется исправлять ошибки прошлых поколений.

Ежегодно вырубаются огромные лесные массивы, загрязняются водоёмы, уничтожаются редкие виды животных и растений. Порой складывается впечатление, что люди ведут войну с природой. На самом деле это война с самим собой. Мы начинаем забывать о том, что человек не царь 
природы, а составная ее часть, что Земля - наш общий дом, и о нём нужно заботиться, как о своей крепости. Человек на Земле - старший по разуму и по старшинству, ему отведена иная роль. Он должен быть рачительным хозяином и помнить обо всех, кто живёт в его огромном доме - планете по имени Земля. Однако для большинства дом ограничивается пределами своей квартиры, дачи. Немногие из людей назовут среди важнейших жизненных ценностей чистый воздух и воду. Большинство просто не думают о них, считая чем-то, безусловно, полагающимся человеку, незыблемым, неистребимым. А часто ли кто-нибудь из нас задумывается: надолго ли хватит земных ресурсов при таком их беспорядочном и интенсивном использовании? Каждый думает примерно так: «На мой век хватит!» Поэтому от природы, как от слуги, требуют абсолютного служения и подчинения, не спрашивая, согласна ли она играть такую роль.

Бережное отношение должно распространяться и на сохранение ресурсов, и на воду, и на воздух. Пора остановиться, прекратить самоистребление. Важно понять, что абсолютно от каждого человека зависит судьба нашего общего дома под названием планета Земля. Сегодня окультурен весь земной шар, на котором не найти клочка, прямо или косвенно не свидетельствующего о присутствии человека. Но сегодня разросшееся древо культуры грозит заглушить и погубить древо жизни. Однако человек может предотвратить уход Земли. И чтобы выжить, ему нужно пересмотреть свои взгляды на сочетание искусственного и естественного в его окружении и перестраивать природопользовательную практику. Итак, первый шаг к этому: необходимо новое видение Земли, сегодняшней Земли как уникальной планеты с её главной достопримечательностью - жизнью.

\section{Список литературы}

1. Плешаков А.А. Окружающий мир, 3 класс: учеб. для общеобразоват. учреждений: в 2 ч./ А.А. Плешаков. - М. Просвещение, 2010

2. Большая энциклопедия

3. Большая книга вопросов и ответов «Экелю» 2002г

4. http://russian-water.ru/russian-water-main/80-urok-chistoj-vodi.html «Методические материалы к Всероссийскому Уроку Чистой воды».

5. www.water.ru/bz/likbez/aboutw.shtml «О воде» 
6. Внеклассные мероприятия: 3 класс/ Авт.-сост. Л.Н. Яровая, О.Е. Жиренко, Л.П. Барылкина, Л.А. Обухова - 3-е изд. перераб. и доп.. - М.: BAKO, 2007 